\title{
Cocción de clínker de cemento portland en hornos rotatorios
}

\author{
VAGN IOHANSEN \\ (Laboratorios F. L. SMIDTH \& CO.) \\ Trabajo traducido del inglés y expuesto por el Prof. Dr. JOSE CALLEJA \\ Vicedirector del IETCC
}

\section{INTRODUCCION}

La reacción más importante durante la cocción del clínker de cemento portland es la formación de silicato tricálcico a partir de silicato bicálcico y de cal:

$$
\mathrm{C}_{2} \mathrm{~S}+\mathrm{CaO} \rightarrow \mathrm{C}_{3} \mathrm{~S}
$$

A temperaturas inferiores a $1.200^{\circ}-1.300^{\circ} \mathrm{C}$ el crudo se deshidrata y se descarbonata, y se forman silicatos, aluminatos y ferritos cálcicos. A temperaturas superiores se forma fase líquida y $\mathrm{C}_{2} \mathrm{~S}$ rápidamente. Después se forma $\mathrm{C}_{3} \mathrm{~S}$ (1) y su formación está regida por la difusión de $\mathrm{CaO}$ a través de la fase líquida.

Esto significa que la velocidad de formación de $\mathrm{C}_{3} \mathrm{~S} \multimap$ de consumo de $\mathrm{CaO}-$ es proporcional a la cantidad de fase líquida y a la temperatura.

En la bibliografía se ha dado cuenta de diversas experiencias en las que se ha investigado este fenómeno $(2,3,4,5$ y 6$)$.

$$
\mathrm{T} \sim 1.300^{\circ}-1.500^{\circ} \mathrm{C}
$$

Compuestos formados a

temperaturas bajas

$$
\begin{gathered}
\frac{\text { reacción }}{\text { rápida }} \rightarrow \mathrm{C}_{2} \mathrm{~S}+\mathrm{CaO}+\mathrm{FL} \frac{\text { reacción }}{\text { lenta }} \rightarrow \mathrm{C}_{3} \mathrm{~S}+\mathrm{FL} \\
(\mathrm{FL}=\text { Fase líquida })
\end{gathered}
$$

En lo que sigue voy a hacer un resumen de dichas experiencias y de sus resultados.

$\mathrm{Si}$ suponemos que se tienen dos clínkeres, uno $\left(\mathrm{C}_{1}\right) \mathrm{C}_{3} \mathrm{~S}-\mathrm{CaO}$ y otro $\left(\mathrm{C}_{2}\right) \mathrm{C}_{3} \mathrm{~S}-\mathrm{C}_{2} \mathrm{~S}$, formados a $1.500^{\circ} \mathrm{C}$ y en equilibrio, tal como indica la figura 1, y que se hacen reaccionar a dicha temperatura, a un lado y otro de la superficie original de contacto se formará una

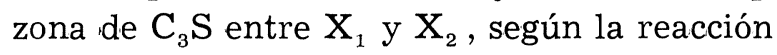

$$
\mathrm{C}_{2} \mathrm{~S}+\mathrm{C} \rightarrow \mathrm{C}_{3} \mathrm{~S}
$$

Esto es lo que cabe esperar según la teoría, la cual predice además que la anchura de la zona aumenta proporcionalmente a la raíz cuadrada del tiempo, tal como indica la figura 2. 
Experiencias análogas realizadas con una serie de clínkeres con distintos módulos silícicos han demostrado que la anchura de la zona de reacción varía según muestra la figura 3 .

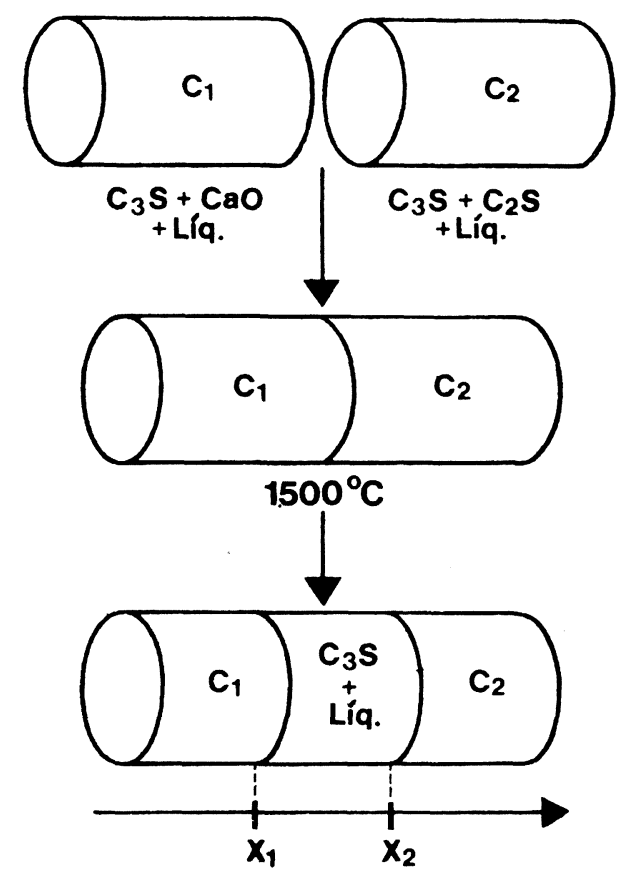

Fig. 1a.-Acoplamiento o par de difusión para determinar la velocidad de formación del $C_{3} S$.

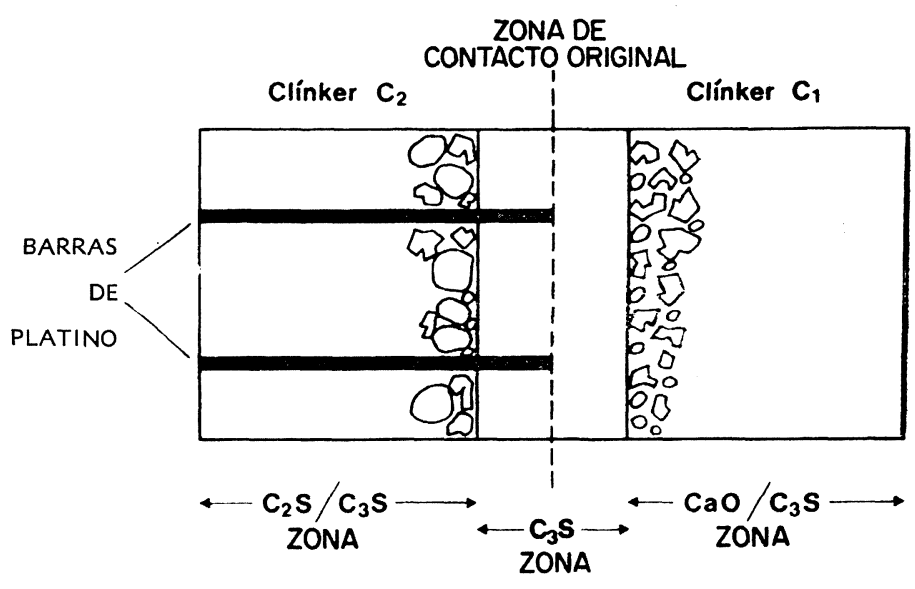

Fig. 1b. Sección del acoplamiento y de la zona de difusión.

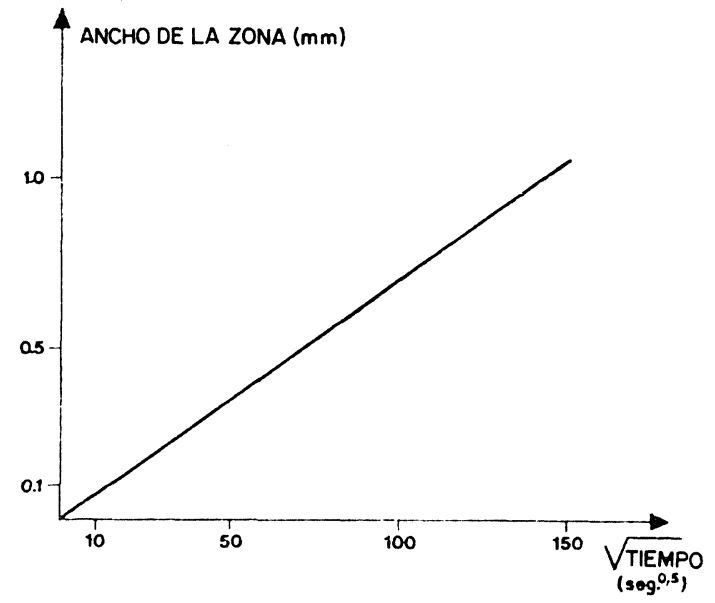

Fig.2.-Anchura de la zona en función de la raiz cuadrada del tiempo.

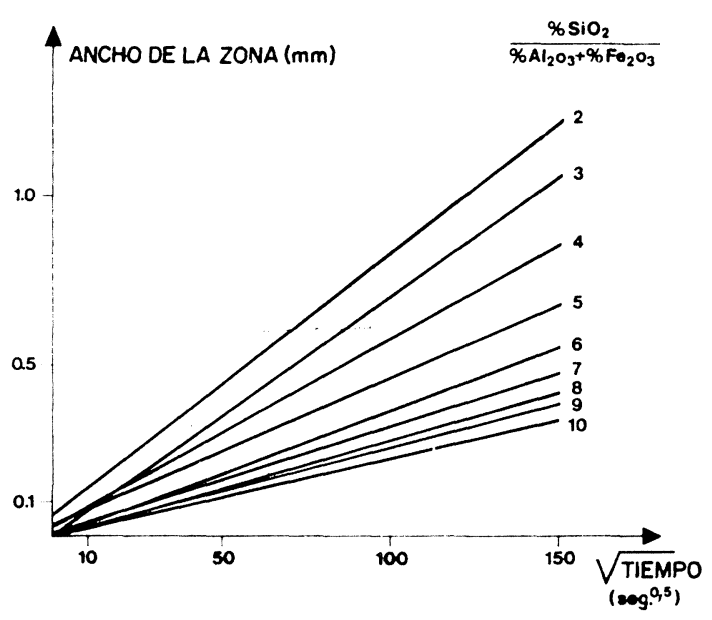

Fig. 3.-Lo mismo que en la figura 2, para distintos módulos silícicos.

En ella la pendiente de las rectas es proporcional a la velocidad de formación de $\mathrm{C}_{3} \mathrm{~S}$.

Cuando se trasladaron los resultados expuestos en la fig. 3 a sistemas de clínkeres con igual cantidad de fase líquida a las temperaturas de reacción, resultó que la velocidad de crecimiento de la zona $\mathrm{C}_{3} \mathrm{~S}$ fue la misma en todos los casos, tal como indica la figura 4. 
Esto implica que la dependencia existente entre la velocidad de formación de $\mathrm{C}_{3} \mathrm{~S}$ y el módulo silícico significa que dicha formación es proporcional a la cantidad de fasa líquida a la temperatura en cada caso (fi. 5).

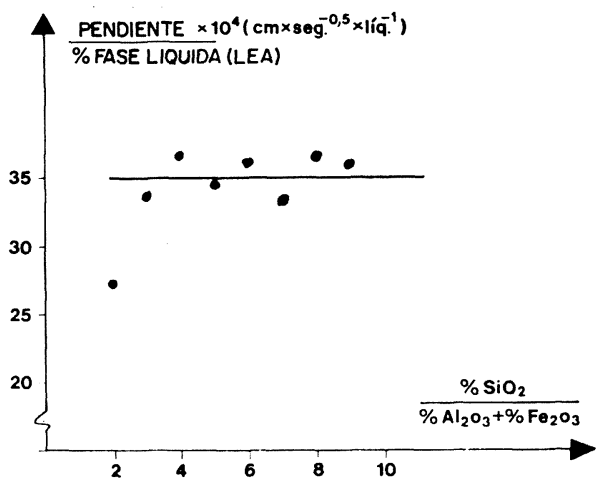

Fig. 4.- Relación pendientes de rectas de la figura $3 / \%$ de fase líquida, frente a módulos silícicos.

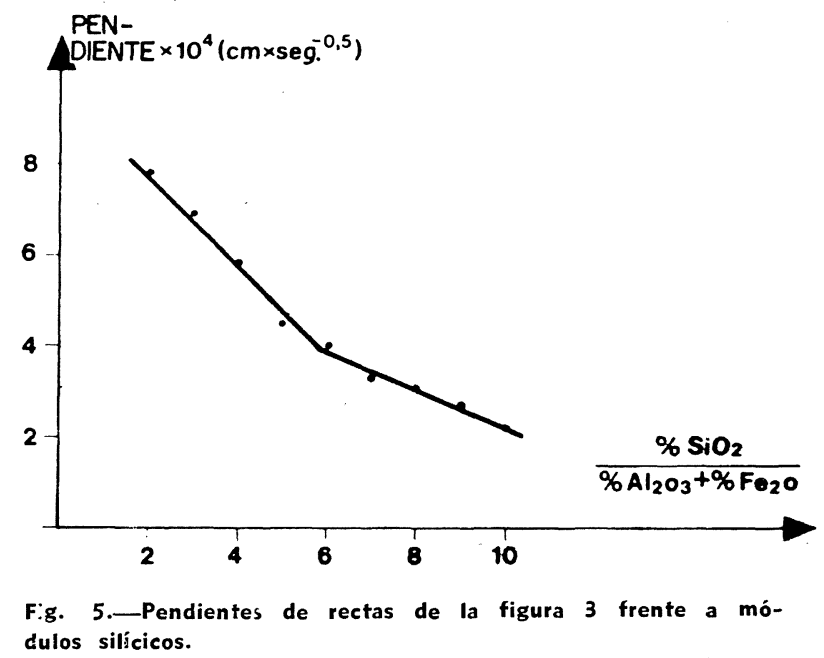

dulos silícicos.

¿Qué se puede hacer para aumentar la formación de $\mathrm{C}_{3} \mathrm{~S}$ en tales sistemas?

Hay dos parámetros que se pueden hacer variar:

1. Se puede aumentar la constante de difusión də $\mathrm{CaO}$.

2. Se puede modificar la cantidad de fase líquida.

Al aumentar la temperatura se puede incrementar el coeficiente de difusión, y con él la velocidad de formación del $\mathrm{C}_{3} \mathrm{~S}$. Sin embargo, ésta no es una solución práctica, a causa del consumo calorífico, de la duración del refractario, etc. Con el fin de mantener el consumo lo más bajo posible, se mantiene la temperatura al mínimo tolerable. Por la misma razón, la solución de aumentar la cantidad de fase líquida elevando la temperatura es igualmente mala. Además, la cantidad de fase líquida no depende en gran medida de la temperatura.

La cantidad de fase líquida se puede hacer variar mediante agentes fundentes o mineralizadores. Por adición de $\mathrm{Al}_{2} \mathrm{O}_{3}$ y $\mathrm{Fe}_{2} \mathrm{O}_{3}$ el módulo silícico disminuye y, como ya está demostrado, esto influye grandemente en la velocidad de reacción. Si se añade $\mathrm{Fe}_{3} \mathrm{O}_{3}$ solamente, se logra una disminución del módulo alumínico o de fundentes, lo cual da por resultado un aumento de la cantidad de fase líquida a temperaturas más bajas. Pero, debido a estas temperaturas más bajas, la formación de $\mathrm{C}_{3} \mathrm{~S}$ se hace más lenta. Sin embargo, como se verá después, la formación de fase líquida a estas temperaturas bajas contribuye a mejorar la nodulización del material en la zona de cocción, dando lugar a una mejora general de la marcha del horno.

Los álcalis que circulan en el sistema del horno dan lugar a fases líquidas a temperaturas inferiores a las de los fundidos del clínker normal. Sería de esperar según eso un cierto efecto en la formación de $\mathrm{C}_{3} \mathrm{~S}$, pero los resultados de experiencias de laboratorio han demostrado que el clínker con y sin álcalis contiene la misma cantidad de cal libre, después de cocido a temperaturas entre $1.400^{\circ}$ y $1.500^{\circ} \mathrm{C}$. 
Se han utilizado fluoruros como fundentes y agentes mineralizadores (1).

Las temperaturas de las primeras fases líquidas que se forman se pueden rebajar en $50^{\circ}$ a $100^{\circ} \mathrm{C}$, pero ello exige del orden de $3 \%$ de $^{\mathrm{CaF}_{2}}$.

No obstante, también hay inconvenientes en el empleo de $\mathrm{CaF}_{2}$, por ejemplo. La alita de este sistema tiene propiedades resistentes inferiores, en comparación con las de la alita del clínker sin $\mathrm{CaF}_{2}$. Por lo tanto, el menor consumo de energía logrado mediante la adición de $\mathrm{CaF}_{2}$ debe ser sopesado frente a una posible reducción de la resistencia del cemento y al costo del propio $\mathrm{CaF}_{2}$.

El fluoruro cálcico en concentraciones mayores que $0,7 \%$ provoca la cristalización de la fase líquida, lo cual puede causar un efecto negativo en la granulometría del clínker resultante.

En general, será ventajoso tener una fase líquida a temperaturas bajas, porque así se puede intensificar el proceso de nodulización.

Respecto de la fabricación de clínker de cemento portland con un contenido normal de $\mathrm{C}_{3} \mathrm{~S}$, parece más razonable cambiar la composición química y la finura del crudo, a fin de modificar su aptitud para la cocción y conseguir una mejor clinkerización, que añadir compuestos que no pertenecen al sistema del clínker de cemento portland.

En lo que sigue vamos a considerar el proceso que rige la aglomeración del material en la zona de cocción y la granulometría del clínker resultante.

También se tratará de la relación entre la aptitud para la cocción y la aglomeración.

\section{FORMACION DEL CLINKER}

La distribución por tamaños del clínker de horno rotatorio, la cual no es de gran interés ni desde un punto de vista químico ni en cuanto a la calidad del cemento, es sin embargo un factor muy importante en el proceso fabril y en la manipulación del clínker, y en este sentido puede tener una influencia indirecta en la calidad del cemento.

El clínker granulado fino, pulverulento, perjudica seriamente a la buena marcha de los enfriadores de parrilla y generalmente acorta de forma muy notoria la vida del refractario en la zona de cocción del horno, ya que el polvo de retorno del enfriador con frecuencia da lugar a la formación de un recubrimiento inestable, poroso y con aspecto de piedra pómez, sobre el forro refractario, en lugar del deseable recubrimiento denso y estable. Además, la manipulación del clínker muy pulverulento es problemática, y su aptitud para la molturación es frecuentemente inferior a la del clínker más grueso, exento de polvo.

La experiencia demuestra que el consumo de energía en los molinos de cemento puede aumentar en un $40 \%$ cuando la granulometría del clínker pasa de ser la de un clínker bien nodulizado, a la de un clínker pulverulento o de aspecto semejante al de la piedra pómez.

La figura 6 presenta una muestra de clínker de un horno que lo produce pulverulento.

Durante el enfriamiento las partículas finas se aglomeran en una estructura que recuerda la de la piedra pómez. Este tipo de clínker se caracteriza por el crecimiento simultáneo de partículas de alita muy grandes y adyacentes.

En lo que sigue vamos a describir un modelo cualitativo de proceso que controla la granulometría del clínker producido en los hornos rotatorios. 
Consideraciones acerca de la formación del clínker, especialmente con respecto a la aglomeración, han conducido a un modelo en el que compiten dos procesos:

1) Uno es el de la aglomeración y rodulización física del material en la zona de cocción, a causa de la formación de la fase líquida del clínker.

2) El otro es la formación y el crecimiento de partículas de $\mathrm{C}_{3} \mathrm{~S}$ que contrarrestan el proceso de nodulización.

La aglomeración y la nodulización en cilindros o tambores es un proceso bien conocido en muchas industrias. Las partículas se mantienen juntas por las fuerzas capilares del líquido. La teoría y las experiencias llevadas a cabo han demostrado que la velocidad de

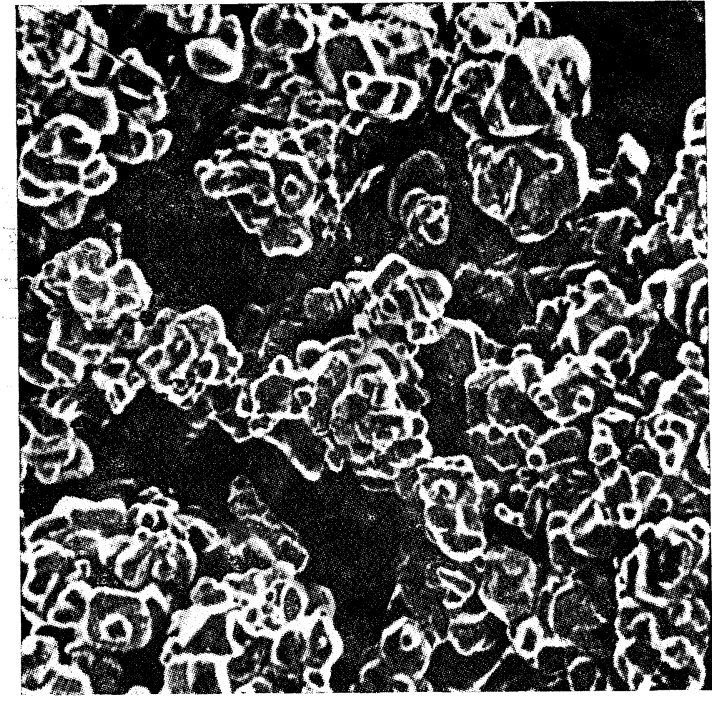

Fig. 6.-Microfotografía de clínker pulverulenło. formación de los nódulos es una función de la cantidad de líquido, del tamaño de las partículas y de la velocidad de giro - número de revoluciones- del tambor. De una forma metódica es posible describir el diámetro medio, así como la distribución por tamaños - granulométrica-, en función de los parámetros señalados.

Existen buenas razones para suponer que el proceso de aglomeración en un horno rotatorio está determinado por los mismos principios físicos.

Al comienzo de la zona de cocción tenemos un sistema formado por partículas sólidas de material y por una fase líquida. La figura 7 presenta la cantidad de fase líquida en función de la temperatura, según la fórmula de DAHL.

El líquido se forma en un intervalo estrecho de temperatura, a $1.350^{\circ} \mathrm{C}$, aproximadamente. Por encima de esta tempérâtura la cantidad de fase líquida aumenta poco, pudiéndose considerar como constante; así puede tener lugar la nodulización, con tal de que las partículas no sean demasiado gruesas.

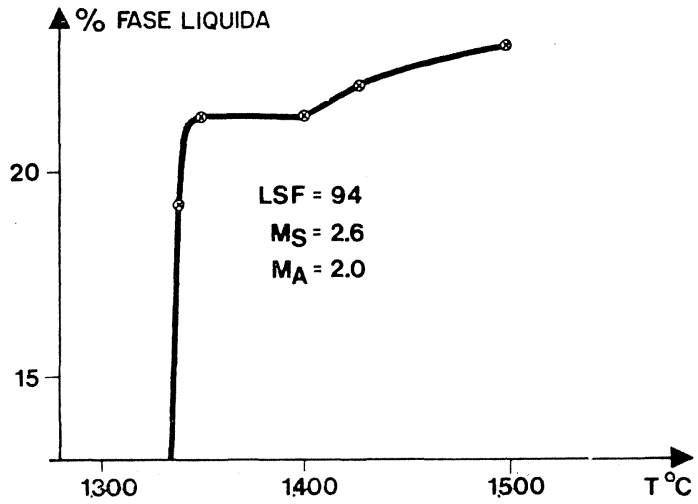

Fig. 7.- $\%$ de fase líquida en función de la temperatura, para un clínker con LSF $=94 \%$, MS $=26 \mathrm{y}$ $M F=2,0$.

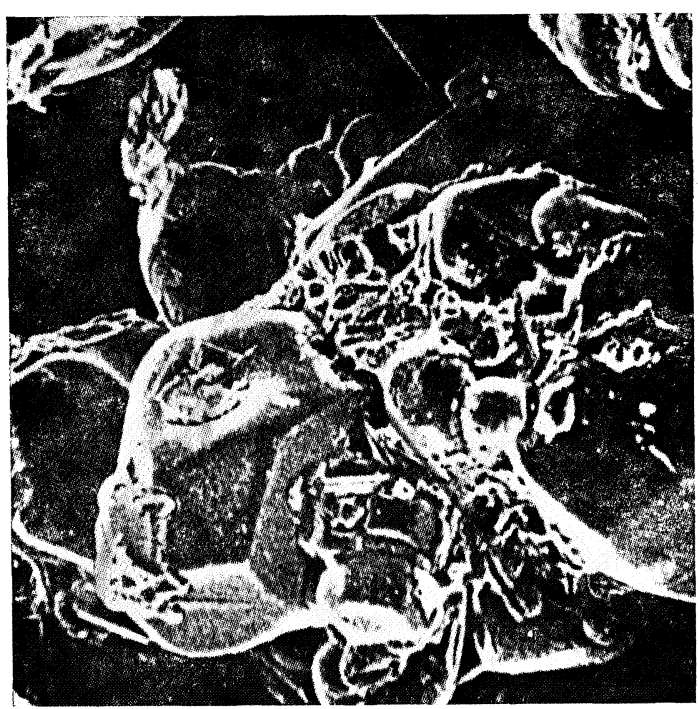

Fig. 8-Partículas de $\mathrm{C}_{3} \mathrm{~S}$ aglomeradas. 
Durante el proceso de cocción en el horno rotatorio se forma $\mathrm{C}_{3} \mathrm{~S}$ en el material. Numerosos estudios de muestras de clínker han puesto en evidencia que un clínker pulverulento y con aspecto de piedra pómez, es decir, un producto no nodulizado, consta de una serie de cristales individuales que se han desarrollado juntos, tal como indica la figura 8.

Cuando dos cristales de $\mathrm{C}_{3} \mathrm{~S}$ coinciden, tienen una gran probabilidad de seguir creciendo juntos para formar partículas gruesas, y un aumento del tamaño de las partículas en un sistema de formación de nódulos retrasa y eventualmente detiene la nodulización.

La figura 9 muestra esquemáticamente la combinación de la nodulización producida por la fase líquida, por una parte, y el impedimento debido a la formación de partículas de $\mathrm{C}_{3} \mathrm{~S}$, por otra. La curva superior presenta el tamaño medio de los nódulos; las inferiores ponen de relieve la formación de $\mathrm{C}_{3} \mathrm{~S}$ frente al tiempo, y ofrecen las situaciones para distintas temperaturas medias de la zona de cocción, de tal manera que cuanto mayor es la temperatura, mayor es también la velocidad de formación de $\mathrm{C}_{3} \mathrm{~S}$.

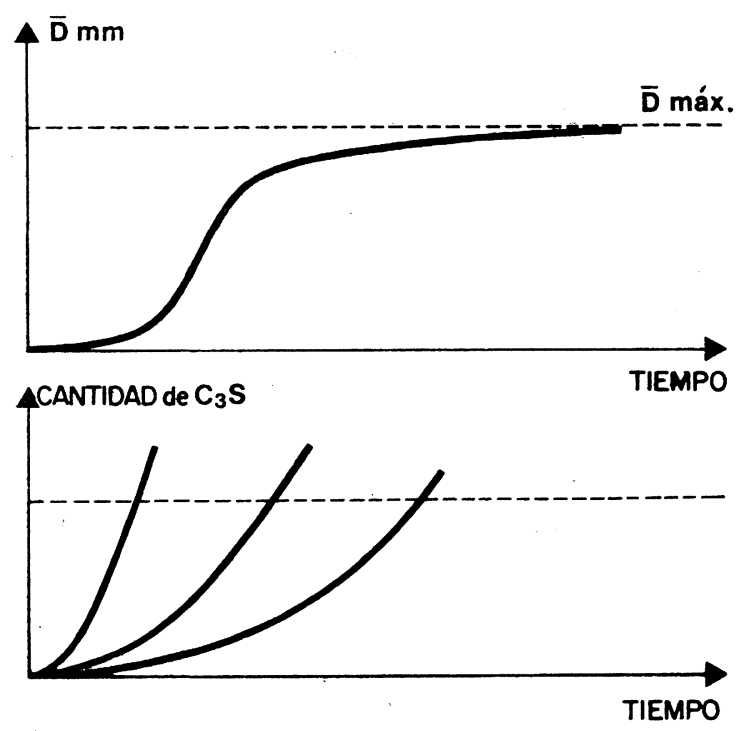

Fig. 9.- $\bar{D}=$ tamaño medio de los nódulos. $\bar{D}_{\max }=$ tamaño medio máximo de los nódulos. La parte inferior representa la farmación de $C_{3} S$ en función del tiempo. La línea de trazos indica la cantidad crítica de $C_{3} S$ que interrumpe el proceso de aglomeración. Las tres curvas muestran la variación de la velocidad de formación de $\mathrm{C}_{3} S$ en función de la temperatura. Cuanto mayor es ésta, tanto más abrupta es la curva.

Cuanto más $\mathrm{C}_{3} \mathrm{~S}$ se forma, mayor es la probabilidad de tener partículas grandes consistentes en varios cristales de $\mathrm{C}_{3} \mathrm{~S}$ que se han desarrollado juntos.

Para una determinada cantidad de $\mathrm{C}_{3} \mathrm{~S}$ el número de partículas es tan grande que a partir de él la formación subsiguiente de nódulos resulta imposible.

\subsection{El modelo de horno}

Con objeto de manejar el modelo hemos dividido el horno en cinco partes, tal como muestra la figura 10.

Por supuesto que las zonas no son tan definidas como indica el diagrama; están caracterizadas por el efecto dominante del material en las respectivas partes. 


\section{La zona de calentamiento}

Desde la zona de calcinación el material llega a la de calentamiento, con una temperatura aproximada de $900^{\circ} \mathrm{C}$. En esta zona se forma la fase fundida del clínker, en un espacio muy corto del horno. Al observar uno de éstos, tal espacio corresponde al lugar donde comienza el revestimiento duro.
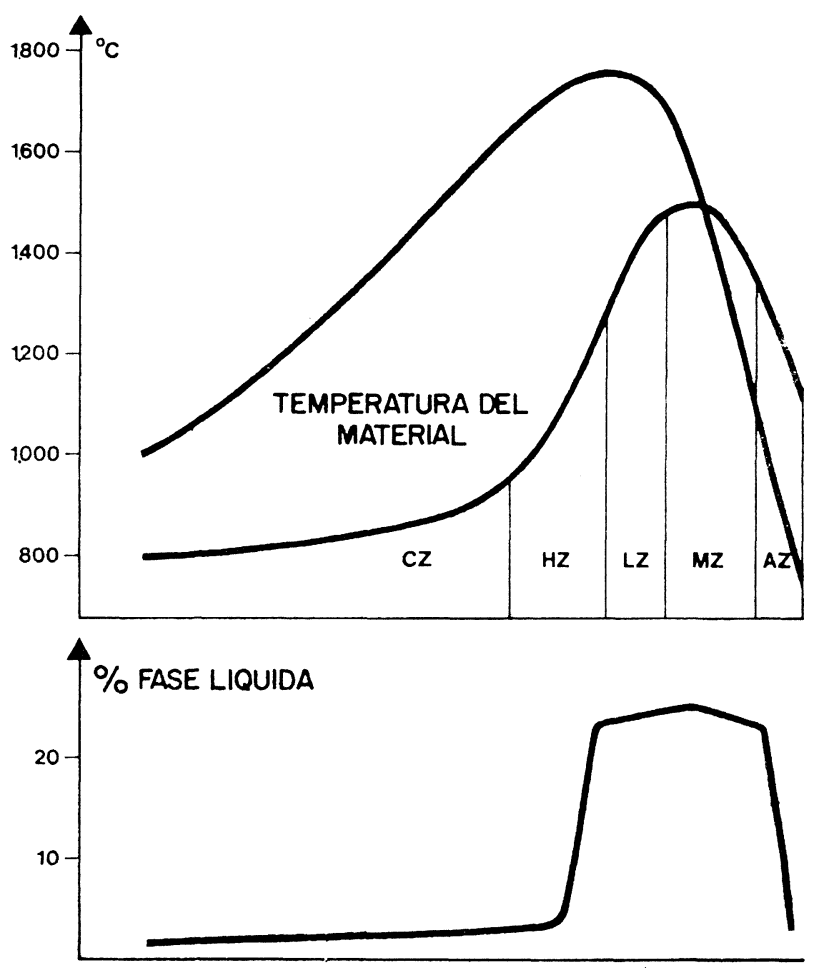

Fig. 10.-Diagrama esquemático de las zonas en el hor-

La figura inferior representa la cantidad de fase liquida correspondiente al perfil de temperatura de la figura superior. Esta muestra la temperatura de los Eases y la del material.

$C Z=$ zona de calcinación.

$\mathrm{HZ}=$ zona de calentamiento.

$L Z=$ zona de fase líquida.

$M Z$ = zona de máxima temperatura

$A Z=$ zona de enfriamiento.

La zona de fase líquida

En esta zona la cantidad y las propiedades de la fase líquida varían muy poco. En ella tiene lugar la nodulización. Y al mismo tiempo que se forma la fase líquida, comienza la formación de $\mathrm{C}_{3} \mathrm{~S}$. Mientras la temperatura es baja, la velocidad de formación de $\mathrm{C}_{3} \mathrm{~S}$ es pequeña, pero a medida que aumenta la temperatura aumenta también la velocidad de formación y, en el momento y lugar en que la cantidad de $\mathrm{C}_{3} \mathrm{~S}$ ha alcanzado el valor crítico, la nodulización cesa.

\section{La zona de máxima temperatura}

Comienza en el mencionado lugar. En esta zona, situada debajo de la llama, el proceso predominante es la formación de $\mathrm{C}_{3} \mathrm{~S}$ y el posterior crecimiento de sus partículas.

\section{La zona de enfriamiento}

Comienza donde y cuando disminuye la temperatura del material. Este puede aglomerarse en ella, pero es debido solamente al enfriamiento y a la solidificación de la fase líquida del clínker. 
Las zonas más importantes en cuanto a la buena aglomeración del material en el horno son la zona de calentamiento y la zona de fase líquida. Ambas deben ser lo suficientemente largas para garantizar la aglomeración.
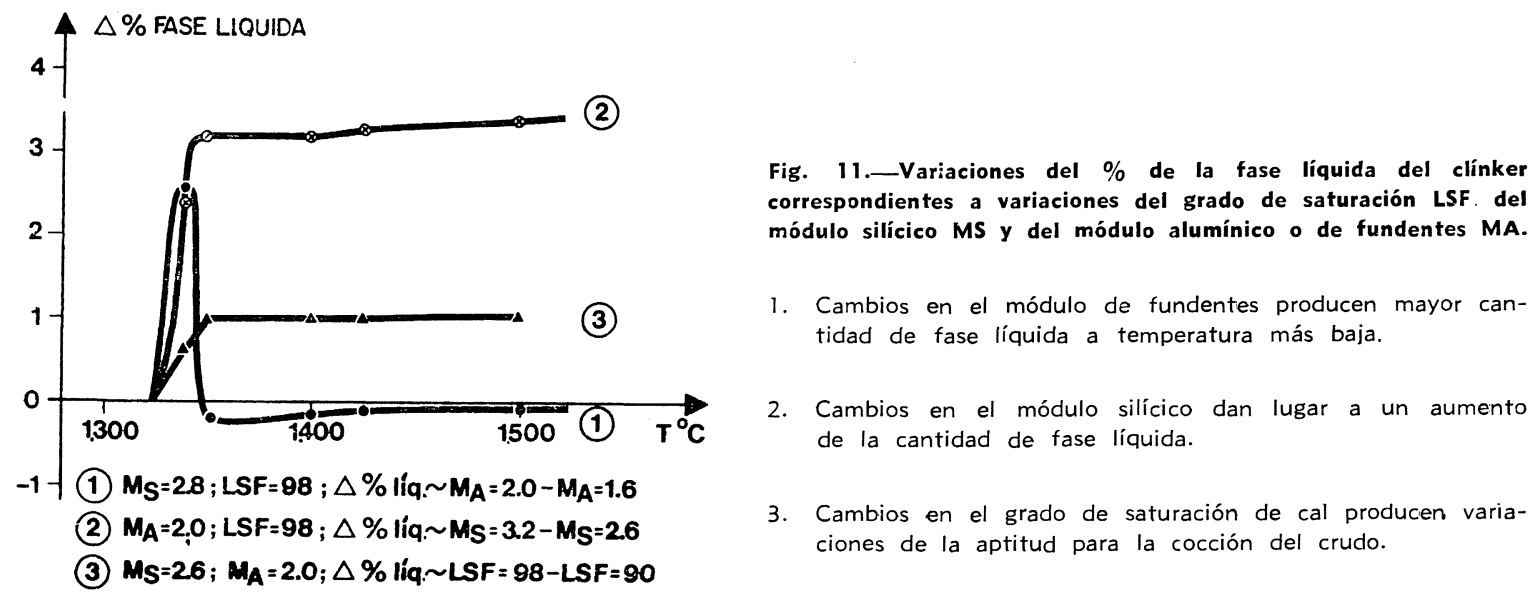

3. Cambios en el grado de saturación de cal producen variaciones de la aptitud para la cocción del crudo.

La figura 11 muestra el efecto de los cambios del grado de saturación de cal y de los módulos silícico y de fundentes en la fase fundida.

\subsection{Modificaciones del crudo}

\section{Disminución del módulo de fundentes}

Mediante esta modificación se consigue formar mayor cantidad de fase líquida a una temperatura más baja. El efecto máximo se logra reduciendo el módulo a 1,6, que es el valor óptimo. Dado que esto no influye en la formación de $\mathrm{C}_{3} \mathrm{~S}$, ello quiere decir que se dispone de más tiempo con bastante fase líquida para la nodulización en el comienzo de la zona de cocción, con lo cual la nodulización se ve favorecida. Lo contrario sucede aumentando el módulo de fundentes.

\section{Disminución del módulo silícico}

Cuando disminuye el módulo silícico aumenta la cantidad de fase líquida. En el caso de un clínker pulverulento bajo de fase líquida, la disminución del módulo silícico mejorará la nodulización.

\section{Disminución del grado de saturación}

Se observa frecuentemente que una disminución del grado de saturación de cal (Lime Saturation Factor - LSF-), por ejemplo, de 98 a $95 \%$, da lugar a una mejor formación del olínker, incluso si dicha disminución no lleva consigo un cambio en la cantidad de fase líquida del clínker. 
La reducción del grado de saturación se traduce en que el clínker es más fácil de cocer. La temperatura necesaria para ello, al ser más baja, implica una reducción de la zona de máxima temperatura en relación con la zona de fase líquida y, por lo tanto, una mejora de nodulización.

Cuando el crudo es duro de cocer la temperatura en la zona de cocción puede ser muy alta, y la zona de máxima temperatura demasiado larga, a costa de las zonas de calentamiento y de fase líquida. Entonces la aglomeración no tiene lugar y el horno produce un clínker pulverulento.

Para sistemas de hornos en los que el perfil de la temperatura es crítico con respecto a una buena o mala aglomeración, consideraciones teóricas demuestran que un aumento del orden de 30 a $40 \mathrm{kcal} / \mathrm{kg}$ de clínker basta para aumentar el contenido de polvo del mismo. Esto ha sido confirmado por observaciones hechas en varias fábricas.

\section{APTITUD PARA LA COCCION}

La aptitud del crudo para la cocción es en cierto modo decisiva para la marcha del horno, en lo que respecta a la buena nodulización del clínker.

Si el crudo es muy difícil de cocer, la mayor temperatura necesaria para ello redunda en un aumento de la longitud de la zona de máxima temperatura, a costa de las otras zonas. En la figura 12 se pueden observar dos situaciones distintas.

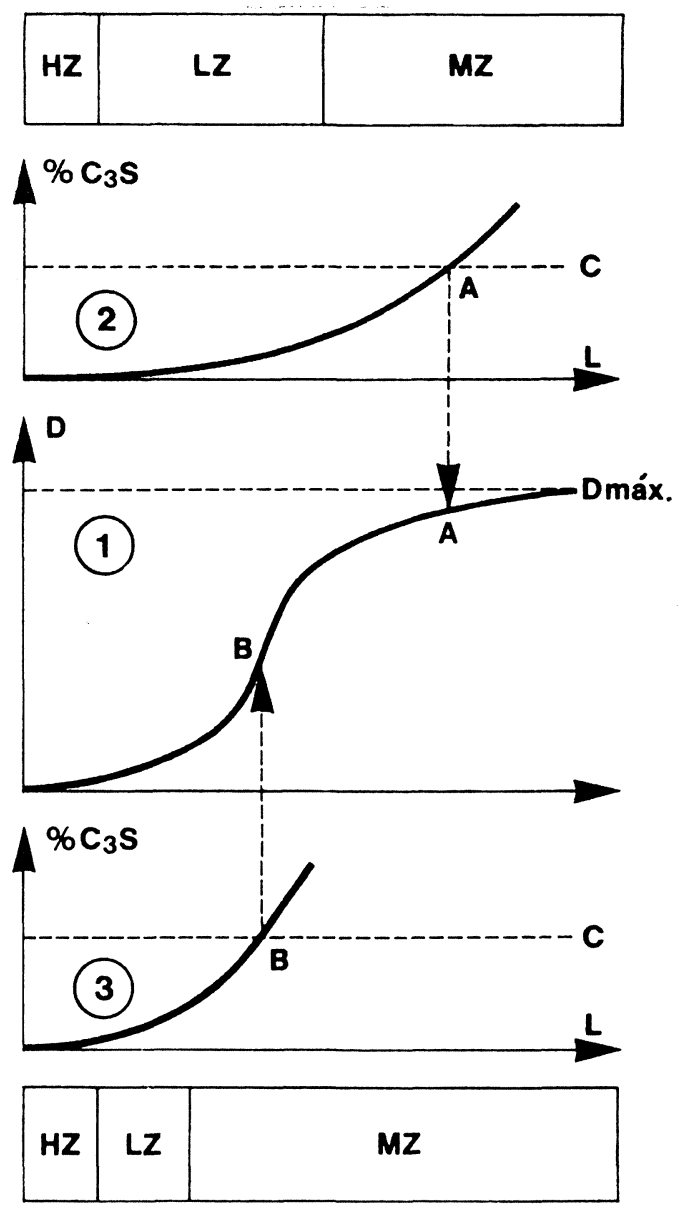

Fig. 12.-Esquema de la posición relativa de la zona de fase líquida $L Z$ y de la zona de máxima temperatura $M Z$ para dos perfiles distintos de temperatura en la zona de cocción.

$\mathrm{C}=$ Cantidad crítica de $\mathrm{C}_{3} \mathrm{~S}$.

$L \quad=$ distancia en la zoha de cocción.

$\bar{D}=$ tamaño medio de los nódulos de clínker.

$\overline{\mathrm{D}}_{\max }=$ tamaño medio máximo obtenible para los nódulos de clinker.

1) $\bar{D}$ es función de la distancia en la zona de cocción.

2) El \% de $\mathrm{C}_{3} \mathrm{~S}$ es función de la distancia en la zona de cocción a temperaturas más bajas, en comparación con la situación (3). 
En una de ellas la zona de fase líquida es más bien larga, y por consiguiente la formación de $\mathrm{C}_{3} \mathrm{~S}$ es un tanto lenta.

La cantidad crítica de $\mathrm{C}_{3} \mathrm{~S}$ se alcanza en el punto $\mathrm{A}$, en el cual se detiene la nodulización.

En la otra situación, y a causa de un crudo duro de cocer, el perfil de temperatura es tal que la zona de fase líquida es corta y la formación de $\mathrm{C}_{3} \mathrm{~S}$ relativamente rápida, por lo que la cantidad crítica de $\mathrm{C}_{3} \mathrm{~S}$ se alcanza ya en el punto $\mathrm{B}$, en el cual el diámetro medio de los nódulos es mucho menor que en el punto A. El resultado es un clínker con un contenido mayor de polvo.

El crudo debe ser fácil de cocer, si se piensa también en el consumo de combustible.

Por ello es importante saber qué parámetros deciden la aptitud para la cocción de un crudo determinado.

En la introducción de esta exposición los resultados de la investigación básica acerca de los procesos de difusión ponían de relieve que la cantidad de $\mathrm{C}_{3} \mathrm{~S}$ que se puede formar

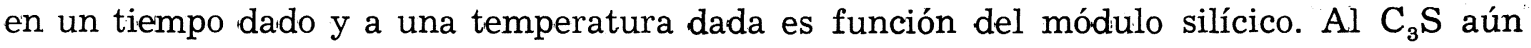
sin formar le corresponde una determinada cantidad de cal libre. Esta debe ser consumida y fijada de un modo semejante al de la formación del $\mathrm{C}_{3} \mathrm{~S}$. Por consiguiente, después de la cocción y durante un tiempo determinado la cantidad de cal libre también puede ser una función del módulo silícico.

$$
\mathrm{CaO} \text { libre } \simeq \mathrm{F} \text { (MS) }
$$

Si varía el grado de saturación aumentando, el consumo de cal libre disminuirá. Por lo tanto, es razonable admitir que la cal libre se pueda describir como una función conjunta del grado de saturación y de otra función dependiente del módulo silícico.

$$
\mathrm{CaO} \text { libre } \sim \mathrm{LSF}+\mathrm{F}(\mathrm{MS})
$$

Al trasladar este principio a los crudos y al clínker es preciso hacer correcciones por los granos gruesos de cuarzo y de calcita. Estos dan lugar a tan grandes variaciones locales de las composiciones químicas en las proximidades de los granos, que contribuyen por sí mismos a la presencia de cal libre.

Por consiguiente, una expresión cualitativa para la cal libre, en virtud de lo anterior, puede ser:

$$
\mathrm{CaO} \text { libre }=\mathrm{a}[\mathrm{LSF}+\mathrm{F}(\mathrm{MS})]+\mathrm{F}^{\prime}
$$

en la que el sumando F' corresponde a la influencia de los granos gruesos del cuarzo y de la calcita.

En los laboratorios de F. L. SMIDTH se ha encontrado que la relación que liga a la cal libre y al módulo silícico es una función lineal de este último:

$$
\mathrm{F}(\mathrm{MS})=\alpha-\beta \cdot \mathrm{MS}
$$

La figura 13 presenta la concordancia entre el contenido de cal libre medido y el calculado.

A partir de la finura de los crudos es posible calcular la cal libre después de la cocción a temperaturas más altas (fig. 14). 
La expresión para la cal libre indica cómo la aptitud para la cocción de un crudo se puede alterar:

1) cambiando el grado de saturación.

2) cambiando el módulo silícico.

3) modificando el contenido de granos de cuarzo gruesos.

4) modificando el contenido de granos de calcita gruesos.

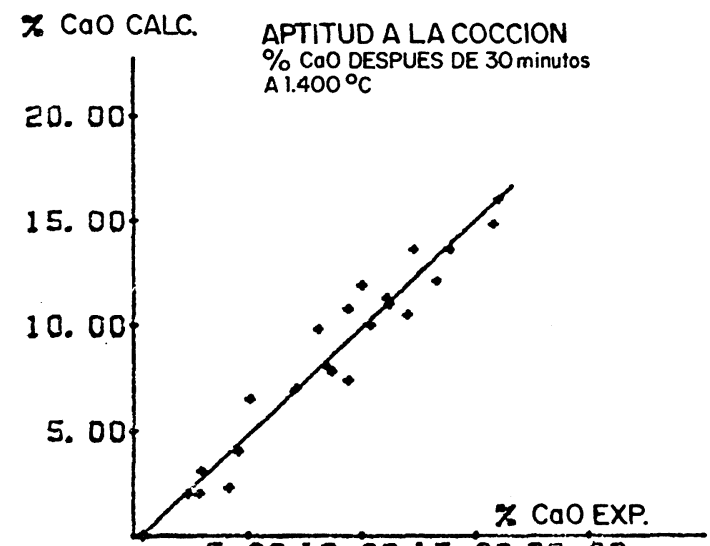

5.0010 .0015 .0020 .00

Fig. 13.-Correspondencia entre la aptitud para la cocción ( $\%$ de cal libre) experimental y la calculada.
I COO CALC.

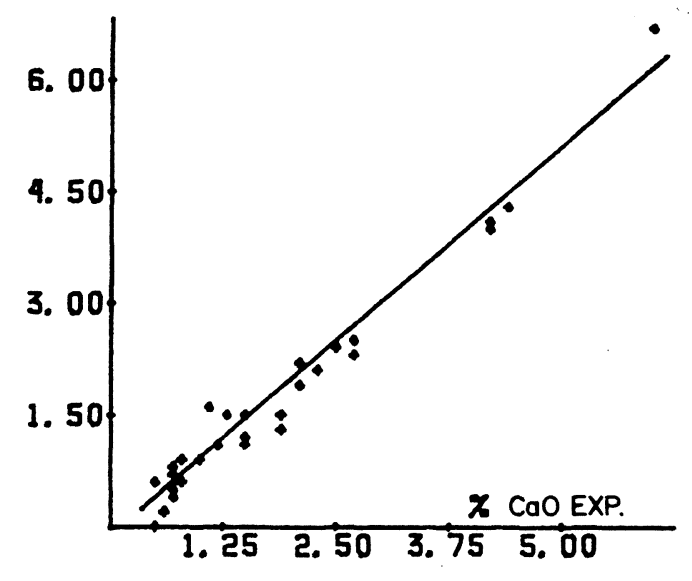

Fig. 14.-Cal libre a $1.450^{\circ}$ y a $1.500^{\circ} \mathrm{C}$ calculada a partir de la cal libre a $1.400^{\circ} \mathrm{C}$.

Las acciones 3) y 4) corresponden a una molienda más fina del crudo, si bien normalmente sólo se muelen los granos de calcita.

Algunos ejemplos demuestran cómo se puede utilizar la expresión de la cal libre cuando se introducen diferentes cambios en la composición química y/o en la finura:

I. La marcha del horno es estabile cuando la aptitud del crudo para la cocción es constante. Si la finura del crudo es asimismo constante, también lo será su aptitud para la cocción, cuando las variaciones del módulo silícico estén contrarrestadas por los correspondientes cambios del grado de saturación.

II. Cambios en la composición química, correspondientes por ejemplo a la variación del grado de saturación de 93 a 99, dan lugar a modificaciones de la aptitud para la cocción como las que muestra la figura 15 . A $1.550^{\circ} \mathrm{C}$ todas las mezclas se cuecen dejando menos de $1 \%$ de cal libre. Pero si el clínker se cuece dejando 1,5\% de cal libre, la temperatura de cocción difiere considerablemente de la anterior, siendo de $1.460^{\circ} \mathrm{C}$ para el crudo con el grado de saturación de $93 \%$, y de $1.529^{\circ} \mathrm{C}$ para el crudo con el grado de saturación de $99 \%$. Respecto de la marcha práctica del horno, una variación del grado de saturación del orden de la mencionada no es irreal, comparada con los valores que normalmente se observan en fábricas de cemento. Corresponde a una desviación típica del $1,5 \%$ en el grado de saturación de la alimentación del horno. Si se cuece para tener un contenido máximo de $1,5 \%$ de cal libre en el clínker, la temperatura de cocción ha de elevarse hasta $1.530^{\circ} \mathrm{C}$ aproximadamente, a fin de garantizar que el contenido de cal libre real no exceda de dicho máximo. 
Las temperaturas más altas del horno pueden influir en la aglomeración, dando lugar a la producción de un clínker pulverulento y creando con ello dificultades en la marcha del horno. Esto hace destacar la importancia de una buena homogeneidad de la alimentación del horno, a fin de obtener una marcha estable de éste y una buena calidad del cemento.

III. Los cambios en la finura del crudo producen asimismo variaciones en la aptitud para su cocción.

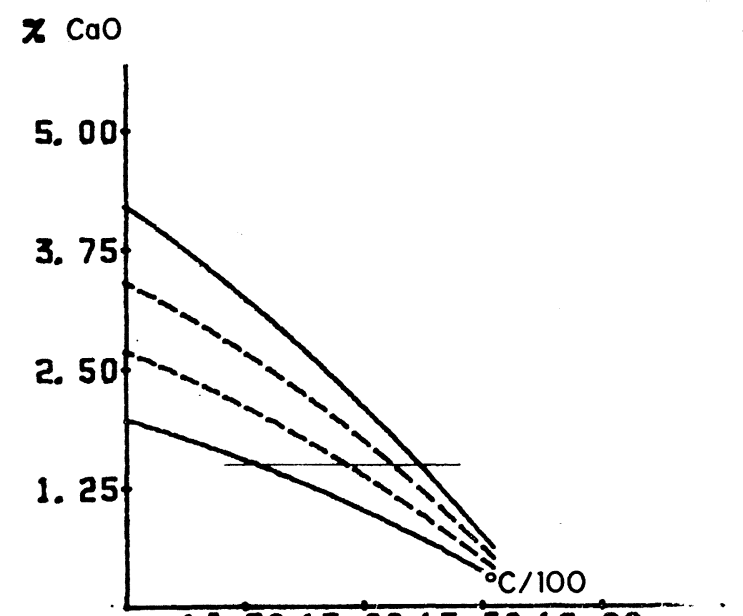

14.5015.0015.5016.00

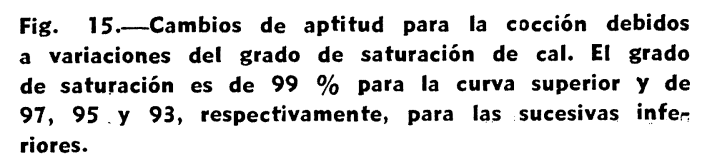

Fig. 15.-Cambios de aptitud para la cocción debidos a variaciones del grado de saturación de cal. El grado $97,95 . y 93$, respectivamente, para las sucesivas inferiores. x $\mathrm{CaO}$

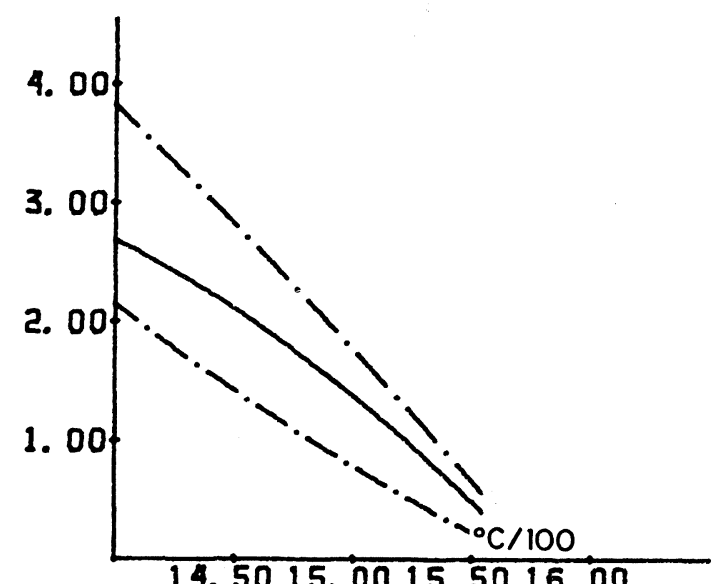

14.5015.0015.5016.00
Fig. 16.-Aptitud para la cocción en función de cambios en la finura del crudo, para un grado de saturación de $95 \%$ y un módulo silícico de 2,5 .

El residuo sobre tamiz de 90 micras fue de $15 \%$ para el crudo representado por la curva superior, y de 10 y $5 \%$ para las dos sucesivas inferiores, respectivamente.

La figura 16 muestra un ejemplo del mismo crudo con tres finuras diferentes.

IV. He aquí un ejemplo práctico tomado de un horno con intercambiador de calor de cuatro etapas y una producción de 4.000 t/día:

El clínker producido era muy pulverulento. Al bajar el módulo silícico de 2,9 a 2,7 se mejoró la clinkerización y se consiguió una marcha regular y estable del horno.

Al mismo tiempo se hizo aumentar el grado de saturación a fin de que la aptitud para la cocción, en conjunto, no variase. Después se hizo disminuir la saturación de 98 a $94 \%$, aproximadamente. Como resultado de todo ello el crudo se coció más fácilmente y se obtuvo un incremento del $15 \%$ en la producción del mencionado horno.

V. En otra fábrica, la marcha del horno se caracterizaba por dar un clínker pulverulento, así como por un factor de marcha relativamente bajo, a causa de frecuentes paradas por obstrucciones en los precalentadores. La granulometría del clínker se mejoró añadiendo $\mathrm{Fe}_{2} \mathrm{O}_{3}$. Esto redujo el módulo de fundentes y, como se indicó antes, dio por resultado un aumento de la cantidad de fase líquida a temperaturas 
más bajas. La mejora de la clinkerización fue seguida por otra mejora en la formación de costra. Todos estos cambios dieron lugar a un menor consumo de combustible, con un ahorro justamente equivalente al precio del material de corrección. Al mejorar la granulometría del clínker y al disminuir la temperatura de cocción el horno se estabilizó y el factor de marcha mejoró notablemente.

\section{B I B L I O G R A F I A}

(1) Frederick M. LeA: The Chemistry of Cement and Concrete. Third edition. Edward Arnold Ltd.

(2) N. H. Christensen and K. A. Simonsen: J. Am. Ceram. Soc. 53 (7) pág. 361-64 (1970).

(3) N. H. Christensen and O. L. Jepsen: ibid 54 (4) 208-10 (1971).

(4) VAGN JOHANSEN: ibid 56 (9) 450-454 (1973).

(5) O. L. JEPSEN and VAGN Johansen: Diffusion controlied reactions in PC clinker. Paper given at the Annual Meeting of the Amr. Ceram. Soc. 1976.

(6) O. L. Jepsen and VAGN Johansen: Influence of $\mathrm{Fe}_{2} \mathrm{O}_{3}$ and $\mathrm{MgO}$ on the diffusion process of the clínker formation. Paper given at the Annual Meeting of the Am. Ceram. Soc. 1972. 


\section{COLOQUIO}

Lo presidió el Sr. ECHEGARAY, actuando de intérprete el Sr. CALLEJA, y transcurrió así:

1. El Sr. RUIZ DE GAUNA pidió ampliación y aclaraciones en relación con el fenómeno de la nodulización. Trasladada la pregunta al Sr. JOHANSEN, y desarrollando y ampliando la respuesta de éste, el Sr. CALLEJA dijo que el crudo pulverulento de alimentación del horno avanzaba dentro de él, por etapas según el sistema, llegando así a una zona en la que, a partir de unos $1.340^{\circ} \mathrm{C}$ se empieza a formar fase líquida, en proporción del 20 al $25 \%$, dependiendo de la composición del crudo y según las conocidas fórmulas de LEA y PARKER. Esta fase líquida, cuya cantidad aumenta un poco entre $1.340^{\circ} \mathrm{C}$ y $1.400^{\circ} \mathrm{C}$ y menos aún entre $1.400^{\circ} \mathrm{C}$ y $1.450^{\circ} \mathrm{C}$, sirve de aglutinante del crudo que no ha fundido, y forma con él nódulos con unos ciertos tamaños y hasta con una determinada curva granulométrica.

Pues bien, el que se formen más o menos nódulos y de unos u otros tamaños, o el que no se lleguen a formar de ninguna manera a partir de un cierto momento y condiciones, depende principalmente - dijo-, de todos los parámetros que ha mencionado el Sr. JOHANSEN. Y entre ellos —continúa el Sr. CALLEJA-, hay uno fundamental que no sólo dificulta la formación de nódulos, sino que puede llegar a impedirla: es el crecimiento rápido de los cristales de silicato tricálcico y su aglomeración. En tales circunstancias se forma un clínker pulverulento, con aspecto de arena de piedra pómez, que por paradójico que parezca resulta más difícil de moler que el clínker granulado normal y tiene peores características, sin contar con que produce una serie de alteraciones y desequilibrios en la marcha del horno, que muchas veces no hay forma de controlar. Es decir - continuó-, hace el proceso de clinkerización mucho más difícil, y en cualquier caso mucho más incómodo, y hasta es probable que más caro, por un mayor consumo de calorías, como consecuencia de una marcha irregular y descontrolada del horno.

El Sr. RUIZ DE GAUNA dijo que tal explicación podría calificarse como de naturaleza macroscópica, y llamó la atención sobre un punto al que no se había hecho referencia en la exposición del Sr. JOHANSEN, cual es el de la importancia que en el aspecto de la velocidad de formación del $\mathrm{C}_{3} \mathrm{~S}$ pueden tener las temperaturas de transformación de las fases polimórficas del $\mathrm{C}_{2} \mathrm{~S}$, diciendo que a esas temperaturas se produce un aflojamiento de redes cristalinas, con movilidad de los elementos de las mismas, y con posibilidad de entrada en ellas de la cal disuelta en la fase líquida y aportada por los fundentes, con el consiguiente aumento de la velocidad de formación del silicato tricálcico. Tal sucede a $1.160^{\circ} \mathrm{C}$, punto de transformación del $\mathrm{C}_{2} \mathrm{~S}-\alpha_{\mathrm{L}}^{\prime}$ en $\mathrm{C}_{2} \mathrm{~S}-\alpha_{\mathrm{H}}^{\prime}$, y también a $1.425^{\circ} \mathrm{C}$, en el cambio del $\mathrm{C}_{2} \mathrm{~S}-\alpha_{\mathrm{H}}^{\prime}$ a $\mathrm{C}_{2} \mathrm{~S}-\alpha$.

Dijo también que estos aspectos de las fases polimórficas del $\mathrm{C}_{2} \mathrm{~S}$ habría que conjugarlos con otro, cual es el contacto con la fase líquida o fundentes. Para un crudo determinado, la cantidad o volumen de ésta en el horno, y en una zona en que se produce la fusión total de los aluminatos y ferritos, es igual al de éstos incrementado en el volumen de los óxidos alcalinos, cálcico, magnésico, silícico, etc., que se van disolviendo 
y que, además, van haciendo aumentar la viscosidad de la fase líquida, lo cual favorece la nodulización. Y que, por el contrario, si se forma pronto mucho $\mathrm{C}_{3} \mathrm{~S}$ se producirá menos fase líquida y menos viscosa, lo que dará lugar a nódulos pequeños y menos abundantes, es decir, sólo los correspondientes a los aluminatos y ferritos presentes.

A esto contestó el Sr. JOHANSEN, a través del Sr. CALLEJA, que nada tenía que decir, por el momento, en cuanto a las transformaciones polimórficas del silicato bicálcico, a las que consideraba dignas de toda atención, pero que, en todo caso, con independencia de la causa y del mecanismo, cuando se forma silicato tricálcico más rápidamente y a más baja temperatura se veía perjudicada la nodulización.

2. A continuación el Sr. AGUANEL intervino acerca de la influencia del tamaño de los cristales del silicato tricálcico en la calidad del cemento, anticipando que hay muchas teorías relativas a la conveniencia o no de que los cristales sean grandes o pequeños, estén bien o mal formados, etc. Preguntó si había un tamaño óptimo, y si podría haber también un tiempo mínimo de permanencia del clínker en las zonas de fase líquida y de máxima temperatura del horno para que los cristales de silicato tricálcico alcanzasen dicho tamaño; y si éste influía en la calidad del cemento.

Contestó el Sr. JOHANSEN diciendo que había considerado el problema, tratando de relacionar el tamaño de la alita con el desarrollo de las resistencias del cemento, pero que no había encontrado ninguna relación. Y que, de hecho, dependiendo de la composición de las materias primas y de la finura del crudo es posible controlar el tamaño de la alita en el clínker cocido.

Continuó diciendo el Sr. JOHANSEN que si se tiene un crudo normal, fino y homogéneo, se puede cocer muy fácilmente hasta llegar a condiciones de equilibrio, obteniéndose entonces cristales de alita muy pequeños; pero que si en el crudo se dan diferencias locales de composición, entonces se encuentra todo un espectro de tamaños de cristales de alita en el clínker.

Una vez traducida la anterior respuesta, el Sr. CALLEJA añadió que, a su juicio, tenía mucha mayor influencia en las resistencias del cemento una variación, aunque pequeña, del contenido de alita del clínker, que una diferencia en el tamaño de los cristales de este componente.

El Sr. AGUANEL dijo referirse no sólo a eso, sino más bien a la influencia del tiempo de permanencia del clínker en la zona de cocción, o a la longitud de ésta, es decir, a si a efectos del tamaño óptimo de los cristales de alita convenía zona de cocción corta o larga.

Contestó el Sr. JOHANSEN diciendo que se habían llevado a cabo experiencias de laboratorio para relacionar el tamaño de la alita con el tiempo de permanencia del clínker a $1.500^{\circ} \mathrm{C}$, con el resultado de que un tratamiento adicional durante 36 horas a dicha temperatura permite duplicar el tamaño medio de los cristales de alita, en relación con el de la correspondiente al mismo clínker no tratado, y que estos resultados coincidían con las conclusiones de un trabajo japonés presentado en el $\mathrm{V}$ Congreso Internacional de Química del Cemento de Tokyo, en 1968, en el cual se dan prácticamente resultados con los mismos valores. Precisó que se procedió cociendo un clínker en unas ciertas condiciones y determinando en una parte de él, después de cocido, el tamaño medio de los cristales de alita; otra parte se sometió durante 36 horas más a cocción en las mismas condiciones anteriores, determinádose asimismo el tamaño medio de los cristales de alita de este clínker recocido, que resultó ser el doble del correspondiente al clínker sin recocer.

El Sr. AGUANEL insistió en el tema diciendo haber leído que los cristales de alita de 40 micras se consideraban óptimos por mejor formados y de mayor energía reticular y ac- 
tividad; pero que también había leído opiniones contrarias, existiendo el problema de si convenían cristales de alita grandes o pequeños. Y que mantenía su pregunta de si había un tamaño óptimo y, en su caso, cómo se conseguía mejor, si con zona de clínkerización corta o larga.

El Sr. JOHANSEN respondió que no creía que hubiese un tamaño óptimo de alita, a los efectos señalados por el Sr. AGUANEL, y que en todo caso se podía lograr obtener cristales de alita del tamaño deseado, dependiendo de la composición del crudo, de su finura (punto éste -el de la finura del crudo- en el que el Sr. JOHANSEN insistió una vez más, e incluso del tiempo de permanencia del material en la zona de clínkerización; con lo cual la cuestión quedó zanjada, no sin antes haber intentado el Sr. JOHANSEN señalan otro aspecto valioso del tema en relación con la conducción del horno, y sentar los principios e ideas básicas que rigen el control del tamaño de los cristales de alita en el clínker.

3. Después preguntó el Sr. AGUANEL acerca de la influencia de la cal libre de clínkeres con una fase líquida muy ferrítica, desde el punto de vista de la expansión.

Al contestar, el Sr. JOHANSEN, ateniéndose a lo que él mismo calificó de "regla práctica del pulgar", diciendo que de momento no se le ocurría sino que, como en el caso general -y sin discriminación-, a mayor contenido de cal libre correspondería una expansión mayor.

El Sr. RUIZ DE GAUNA dijo, en relación con los clínkeres con fase líquida rica en hierro, que el $\mathrm{C}_{3} \mathrm{~S}$ en ellos tiende a tener también más hierro, lo cual hace que la alita se estabilice en sus formas de alta temperatura y no se produzcan transformaciones polimórficas de la misma, tal y como ponen de relieve los resultados del análisis térmico.

El Sr. AGUANEL opinó que la cal libre de los clínkeres ricos en hierro tenía poca influencia en la expansión, a lo cual añadió el Sr. RUIZ DE GAUNA que no lo sabía, pero que parecía ser que los cementos ricos en hierro eran retractivos en el ensayo del autoclave, con lo cual el Sr. AGUANEL se manifestó de acuerdo.

4. El Sr. CORROCHANO a propósito de la formación del clínker, refirió después una anécdota, la cual, con todo el respeto para los teóricos - dijo-, no contribuye a aclarar el panorama. En cierta ocasión - prosiguió-, se dobló la tobera en un horno que producía 2.000 t y entonces, intentando preparar la parada para resolver problemas de mantenimiento, se trabajó durante un par de días con la tobera doblada y el dardo de fuego apuntando al clínker, el cual resultó de un color marrón rojizo, lo que puso en guardia al laboratorio; éste afirmó que aquello no era clínker, ya que por microscopía no se observaba ni un solo cristal. Pero cuando se hizo el ensayo mecánico del cemento, las resistencias que se obtuvieron fueron normales. Es un hecho que el Sr. AGUANEL puede confirmar - dijo-.

El Sr. JOHANSEN opinó que, efectivamente, puede ser que a pesar del aspecto achocolatado del clínker se obtengan buenas resistencias.

El Sr. CALLEJA añadió que lo que probablemente sucedió desde su punto de vista, es que al doblarse la tobera hacia el clínker, la combustión pudo no haber tenido lugar en condiciones normales de aire y, por lo tanto, de oxígeno; y que muy probablemente se efectuó en condiciones reductoras que afectaron en primer término a las fases férricas que pudieron pasar a ferrosas, las cuales tienen en general un punto de fusión más bajo, con lo cual pudo formarse mayor cantidad de fase líquida a una temperatura inferior. Esto probablemente dio lugar a un clínker de granulado más grueso y muy compacto, como si hubiera estado previamente fundido en su totalidad, con poco o ningún aspecto cristalino y de color distinto. En tales condiciones se puede formar, incluso, 
fases no pertenecientes al sistema ordinario del clínker portland. Por otra parte -añadió-, al doblarse la tobera pudo haberse concentrado la llama, y por lo tanto el calor, en una zona en la que se elevó demasiado la temperatura, dando lugar a un clínker al que antiguamente se le llamaba "pasado de fuego", caracterizado precisamente por su color pardo achocolatado y por su aspecto de fundido. Esto - dijo-, suele ir acompañado de exceso de combustible, o de falta de aire para la combustión, y, en todo caso, de una combustión anómala o deficiente, o de unas ciertas condiciones reductoras en el horno, o en una zona afectada del mismo. En cuanto al hecho -añadió- de que el cemento de tal clínker diese resistencias normales, no podría explicarlo, de momento.

El Sr. RUIZ DE GAUNA quiso aclarar algo al respecto, en el sentido de que antes de que se formen los compuestos cristalinos activos del clínker hay fases y compuestos intermedios en formación (en los que intervienen el $\mathrm{CO}_{2} \mathrm{y}$ el $\mathrm{SO}_{2}$ ), poco definidos y formados aún, como constituyentes embrionarios del clínker que son, y que tienen carácter amorfo y actividad hidráulica. Estos compuestos van evolucionando después, en el aspecto de irse purificando de elementos minoritarios. Todo esto —prosiguió-, tiene relación con el crecimiento de los cristales; por ejemplo, los silicatos tricálcico y bicálcico tienen inicialmente muchos más componentes minoritarios disueltos que hacen que sus cristales sean menos perfectos. Pero, a medida que van estando más tiempo en la zona de alta temperatura del horno, van eliminando los componentes minoritarios y aumentando de tamaño, haciéndose más lentos en cuanto a su actividad hidráulica, precisamente porque cuanto más perfecto es un cristal más difícilmente se disuelve y reacciona con el agua. Así puede quedar explicado que componentes que resultan amorfos para la microscopía, incluso para la difracción de rayos $\mathrm{X}$, tengan sin embargo actividad hidráulica. Tales componentes —concluyó-, se pueden detectar más fácilmente por análisis térmico y por espectroscopía infrarroja, que son técnicas idóneas para tal fin.

Según eso - dijo a continuación el Sr. CORROCHANO no sin cierta lógica-, hay que entender que estropeamos el clínker dentro del horno, y que haríamos mejor sacándolo incocido.

A eso respondió el Sr. RUIZ DE GAUNA que no; que esos compuestos iniciales, embrionarios o intermedios de los que él hablaba, se podían mejorar, y que sus características son en parte función del crudo de cada fábrica en particular. En una fábrica determinada - dijo-, el crudo puede ser muy idóneo para que con esas primeras fases el clínker y el cemento tenga ya buenas resistencias, mientras que en otra fábrica el crudo necesite un mayor grado de cocción. Y también - dijo-, el aspecto de la sobrecocción hay que tenerlo en cuenta pues aparte de que con ella se desperdicia energía, puede proporcionar un clínker hidráulicamente más lento.

Al no haber más cuestiones que debatir, el Presidente, Sr. ECHEGARAY, dio las gracias al Sr. JOHANSEN por su exposición, al Sr. CALLEJA por su ayuda en la traducción e interpretación, y a todos los participantes en el Coloquio, por su intervención en el mismo, dando la sesión por terminada. 